\title{
Home advantage in the Commonwealth Games
}

\author{
Girish M Ramchandani (MSc) \\ Darryl J Wilson (MSc)
}

Sport Industry Research Centre, Sheffield Hallam University, Sheffield, UK

\begin{abstract}
Objectives. Research examining the phenomenon of home advantage in international multi-sport competitions is limited to the Olympic Games. This paper investigates the prevalence of home advantage in the Commonwealth Games. The paper also explores the relative impact of travel on performance in the Commonwealth Games.

Methods. Home and away performances for all previous host nations were examined using the standardised measure of market share, regarded by recent European studies as the most robust indicator of a nation's sporting performance. For each host nation, the host effect was calculated as the difference between their average home and away performances. Furthermore, the market share values for each host nation were analysed relative to the distance travelled by them (in terms of the number of time zones crossed) in every edition. This exercise was extended to all nations that have sent a team to the Commonwealth Games in the post-war era.

Results. The research found that, with the exception of England, all previous host nations experienced a positive host effect in the Commonwealth Games. Furthermore, for the majority of nations it was found that performance is negatively correlated with distance travelled. In other words, as distance travelled increases, performance deteriorates

Conclusion. The findings suggest that future host nations of the event can expect to achieve an elevated level of performance when competing on home soil. This may in part be attributable to their athletes not having travel outside their own time zone. Direction for future research is offered.
\end{abstract}

\section{Introduction}

The occurrence of home advantage in sport is generally well documented and has been shown to exist in a variety of sports and events. ${ }^{1-9}$ However, the Olympic Games is the only multi-sport competition of global significance in which the phenomenon has been extensively examined. ${ }^{1,2,9}$ The Commonwealth Games, often referred

\section{CORRESPONDENCE:}

GM Ramchandani

A118 Collegiate Hall, Collegiate Crescent

Sheffield S10 2BP

Tel: +44 (0) 1142255461

E-mail: g.ramchandani@shu.ac.uk to as the 'Friendly Games', is arguably the second most significant multi-sport international sporting competition, behind the Olympics. Furthermore, some of the sports historically contested in the Commonwealth Games (e.g. lawn bowls) are not part of the Olympic programme. Therefore the consideration of the Commonwealth Games provides a different dimension to home advantage research.

Given that 2010 is a Commonwealth Games year, now is perhaps an opportune time to investigate how host nations have historically performed in the event. The ultimate aim of this article is to understand whether or not hosting the Commonwealth Games might lead to a competitive advantage in performance. We also investigate the role of travel in shaping performance in the Commonwealth Games.

The Commonwealth is a voluntary alliance of 53 nations spread across the globe. Sport is a key part of the Commonwealth's identity, and Commonwealth heads of government have recognised the benefits of physical activity and the importance of sport as an effective instrument for social and economic development (see: http://www.thecommonwealth.org/subhomepage/143537/). The prominence of sport within the Commonwealth brand is expressed via the Commonwealth Games held every four years. Although there are 53 Commonwealth nations, there are at present 71 Commonwealth Games Associations (CGAs) that can enter a team in the Commonwealth Games, as one nation can have multiple CGAs. For example, the UK is a single Commonwealth nation but consists of seven CGAs - England, Guernsey, Isle of Man, Jersey, Northern Ireland, Scotland and Wales - all of which compete in the Commonwealth Games as separate nations.

Table I illustrates the evolution of the Commonwealth Games. The inaugural edition took place in Hamilton, Canada, in 1930, with 11 countries and 400 athletes contesting 6 sports. Since then there have been 17 editions of the event, with the most recent being in Melbourne, Australia, in 2006. Attendance at each edition of the Commonwealth Games has steadily increased to the point that in 2002 all Commonwealth nations were represented in Manchester, England. As the number of nations taking part has increased, so too have the number of athletes, events and disciplines.

The number of teams competing in the Commonwealth Games is dependent upon the number of nations in the Commonwealth itself as, from year to year, nations are admitted and suspended for various reasons. The very early editions of the Commonwealth Games (1930 - 1938) were characterised by few participant nations and a limited number of sports. Consequently, and also because the Commonwealth Games were suspended around the time of World War II, the research concentrates on the post-war editions of the event, i.e. from 1950 to 2006.

It may be argued that competition in the Commonwealth Games has increased over time by virtue of more nations and more athletes taking part. To illustrate this point, the athlete to event ratio has increased from $6.70(590 / 88)$ in 1950 to 16.53 (4 049/245) in 2006, which indicates that the intensity of competition has increased during this period. Over and above the typical motives cited by nations 
for staging an event of this magnitude (e.g. economic, regeneration, international recognition, socio-cultural, sport development, etc.), hosting the Commonwealth Games could also be a strategic approach to combat the increase in competition if home advantage is likely - at least as a short-term solution.

\section{Methods}

The method used to conduct this research involved secondary analysis on the results database of the Commonwealth Games from 1950 to 2006 . The event takes place every 4 years and thus the results are based on 15 editions of the event. The results data for each edition were sourced from the official Commonwealth Games website (http://thecgf.com/games/games_index.asp?linkresults=1). In total eight nations were eligible for inclusion in the home advantage calculations on account of having hosted the event on at least one occasion since 1950, as identified in Table I. Eligible nations in-

\begin{tabular}{|llcccr|}
\hline \multicolumn{5}{|c}{ TABLE I. Growth of the Commonwealth Games } & \\
\hline Year & Host & Nations & Sports & Events & Athletes \\
1930 & Canada & 11 & 6 & 59 & 400 \\
1934 & England & 16 & 6 & 68 & 500 \\
1938 & Australia & 15 & 7 & 71 & 464 \\
1950 & New Zealand & 12 & 9 & 88 & 590 \\
1954 & Canada & 24 & 9 & 91 & 662 \\
1958 & Wales & 35 & 9 & 94 & 1122 \\
1962 & Australia & 35 & 9 & 104 & 863 \\
1966 & Jamaica & 34 & 9 & 110 & 1050 \\
1970 & Scotland & 42 & 9 & 121 & 1383 \\
1974 & New Zealand & 38 & 9 & 121 & 1276 \\
1978 & Canada & 46 & 10 & 128 & 1474 \\
1982 & Australia & 46 & 10 & 142 & 1583 \\
1986 & Scotland & 26 & 10 & 163 & 1662 \\
1990 & New Zealand & 55 & 10 & 204 & 2073 \\
1994 & Canada & 63 & 10 & 217 & 2557 \\
1998 & Malaysia & 70 & 15 & 213 & 3633 \\
2002 & England & 72 & 17 & 281 & 3679 \\
2006 & Australia & 71 & 16 & 245 & 4049 \\
\hline
\end{tabular}

cluded Australia, Canada, New Zealand (each with 3 home editions), Scotland (2 home editions), England, Jamaica, Malaysia and Wales (1 home edition each).

The Commonwealth Games medal table ranks participating nations in descending order of gold medals won, although such tables are not officially recognised as being an order of merit. There exist alternative approaches to performance measurement in international sport and different performance measurement systems can give conflicting diagnosis of a nation's performance. Recent European studies ${ }^{10,11}$ argue that the most robust indicator of nations' sporting performance is 'market share'- a standardised measure of total achievement whereby the total medals won in an event are converted into points (gold $=3$, silver $=2$ and bronze $=1$ ) and the points won by a given nation are subsequently expressed as a percentage of the total points available. For example, if a nation wins 20 gold medals ( 60 points), 15 silver medals (30 points) and 10 bronze medals (10 points) then the total number of points won is $100(60+30+10)$. Assuming the total number of points available is 1000 then its market share would be $10 \%$ (i.e. 100/1 000).

Market share calculations were undertaken for all host nations across each edition of Commonwealth Games between 1950 and 2006. For each host nation, home market share performances were then compared against their away market share performances to assess whether home advantage was prevalent.

In order to test whether travel had an impact on performance, the market share values for each host nation were examined relative to the distance travelled by them (in terms of the number of time zones crossed) in every edition. The analysis revealed the nature and strength of the relationship between host nation performance and travel in the Commonwealth Games. This exercise was subsequently extended to all nations that have sent a team to the Commonwealth Games in the post-war era.

\section{Results}

The overall home and away performances for all host nations are summarised in Table II, using the standardised measure of market share.

All things being equal, it might be expected that a nation's average performance at home is comparable with its average performance away from home. However, for seven of the eight nations in Table II market share is higher when competing on home soil, as indicated by a positive host effect for these nations. The magnitude of home advantage, where prevalent, varies by nation, ranging from 0.3

\section{TABLE II. Host nation performance in the Commonwealth Games 1950 - 2006}

\begin{tabular}{|c|c|c|c|c|c|c|c|}
\hline \multirow{2}{*}{ Nation } & \multicolumn{2}{|c|}{ Overall } & \multicolumn{2}{|c|}{ Home } & \multicolumn{2}{|c|}{ Away } & \multirow{2}{*}{$\begin{array}{l}\text { Host effec } \\
\% \text { Points }\end{array}$} \\
\hline & Editions & Average (\%) & Editions & Average (\%) & Editions & Average (\%) & \\
\hline Australia & 15 & 26.9 & 3 & 30.2 & 12 & 26.0 & 4.2 \\
\hline England & 15 & 21.4 & 1 & 18.7 & 14 & 21.8 & $(3.1)$ \\
\hline Canada & 15 & 16.2 & 3 & 21.3 & 12 & 15.0 & 6.3 \\
\hline New Zealand & 15 & 6.2 & 3 & 10.4 & 12 & 5.3 & 5.1 \\
\hline Scotland & 15 & 3.7 & 2 & 5.6 & 13 & 3.4 & 2.2 \\
\hline Wales & 15 & 2.5 & 1 & 2.8 & 14 & 2.5 & 0.3 \\
\hline Malaysia & 13 & 2.0 & 1 & 5.3 & 12 & 1.6 & 3.7 \\
\hline Jamaica & 13 & 1.7 & 1 & 2.4 & 12 & 1.6 & 0.8 \\
\hline
\end{tabular}




\begin{tabular}{|c|c|c|c|c|c|c|}
\hline \multirow{2}{*}{ Nation } & \multicolumn{3}{|c|}{ Best performance (market share) } & \multicolumn{3}{|c|}{ Worst performance (market share) } \\
\hline & Home \% & Neighbour \% & Away \% & Home \% & Neighbour \% & Away \% \\
\hline Australia & 34.3 & & & & & 18.6 \\
\hline Canada & 29.5 & & & & & 6.8 \\
\hline England & & 29.4 & & & & 15.0 \\
\hline Jamaica & & & 3.1 & & & 0.5 \\
\hline Malaysia & 5.3 & & & & & 0.2 \\
\hline New Zealand & 18.4 & & & & & 3.3 \\
\hline Scotland & 6.1 & & & & & 1.5 \\
\hline Wales & & 4.0 & & & & 0.4 \\
\hline
\end{tabular}

percentage points for Wales to 6.3 percentage points for Canada.

In the analysis, England was the only nation for which an adverse host effect was observed. The lack of home advantage in the case of England masks the nation's superior performances in the editions held by its fellow UK home nations and immediate neighbours - Scotland and Wales. To illustrate this point, the average market share for England in the Commonwealth Games held in the UK (at home, in Scotland and Wales) is $26.7 \%$ and $20.7 \%$ when held elsewhere.

Table III highlights the 'best' and 'worst' performances for each host nation and pinpoints the location of such performances in terms of home, away and neighbour editions.

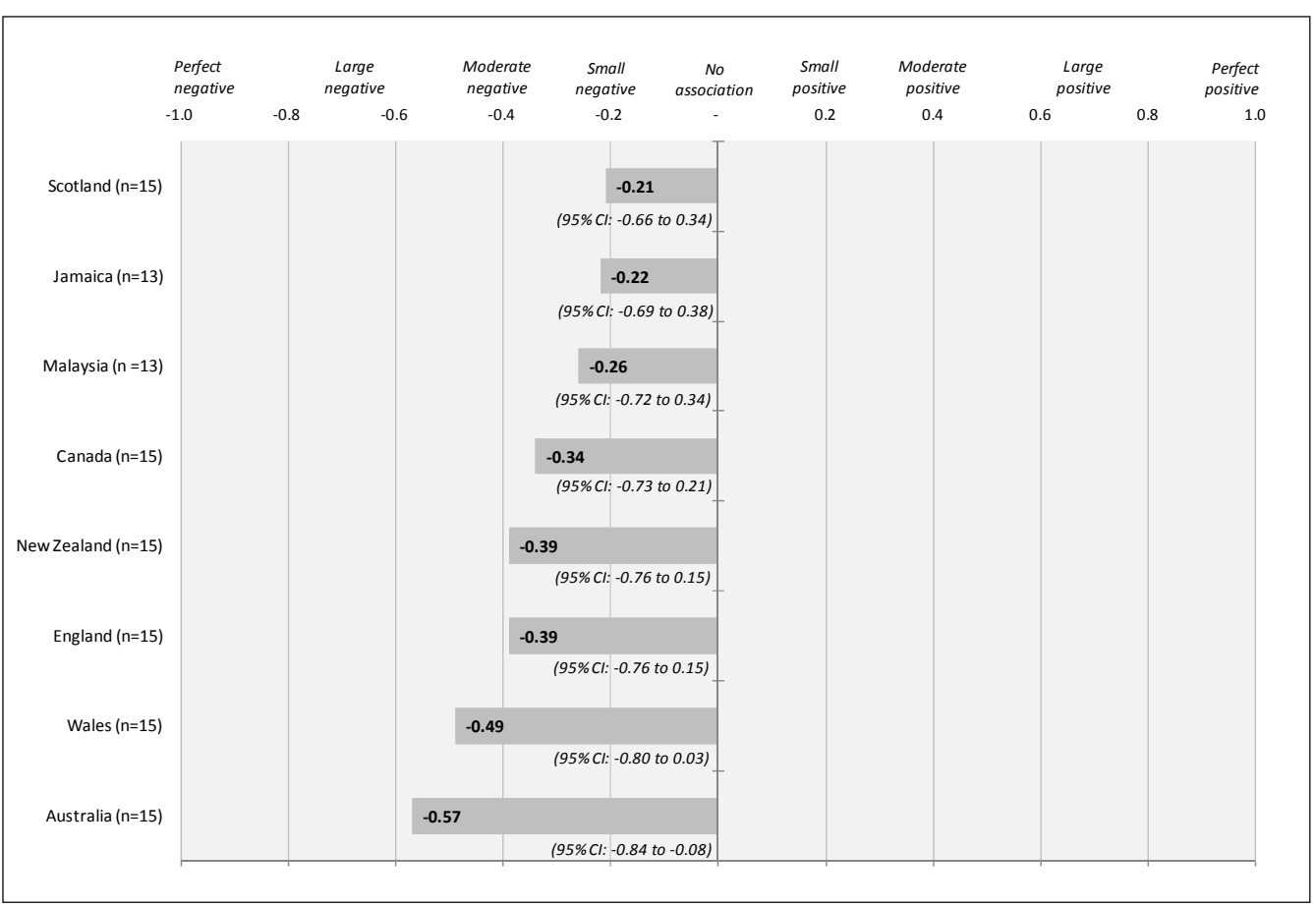

Fig. 1. Travel versus performance in the Commonwealth Games ( $r$ values).

The concept of neighbour edition is introduced to account for the geographical proximity in the case of UK home nations of England, Scotland and Wales and possibly for other host nations. For this purpose, a neighbour was considered to be any nation sharing the same time zone with the host nation.

According to Table III, the most productive market share performance for five of the eight host nations in the Commonwealth Games coincided with their home edition. Furthermore, two of the three instances where nations did not reach their highest level of performance at home occurred on neighbouring soil - performances for both England and Wales peaked in Scotland. Furthermore, the lowest market share returns for all host nations are confined to the 'Away' column in Table III. Therefore, without exception, the least favourable performance was witnessed when not competing at home or in the same time zone. Together these findings draw attention to the implications of competing at home and, to a lesser extent, nearer to home.

Using the number of time zones crossed as an indicator of distance travelled to the host nation, it was possible to plot each nation's performance against the corresponding travel factor (time zone difference from the host nation) across every edition. The exercise revealed that performance was negatively correlated with travel for all host nations. In other words, as distance travelled increases, performance deteriorates. The coefficient of correlation (r) values are presented in Fig. 1.

In order to test whether this finding was limited to host nations or part of a more common phenomenon, we repeated the exercise for all 78 nations that have contested the Commonwealth Games since 1950. Some territories have subsequently merged whilst others are no longer part of the Commonwealth alliance. For the purpose of this research, 23 nations were exempt from the analysis on the basis that they only contested one edition of the event and therefore there is no alternative point of reference available for these nations against which to relate their performance with travel to the host location (e.g. Belize, Brunei, Gibraltar and Sierra Leone). In this regard, the findings relate to 55 'eligible' nations.

Overall, the analysis revealed an inverse association $(r<0)$ between distance travelled and performance for $38(69 \%)$ out of the 55 nations. In other words, for the majority of nations, success in the event diminishes with travel. The magnitude of the correlation varies by nation and by broad geographic region. For example, the 
finding $r<0$ was more widespread among Commonwealth nations from Africa (14/18 nations, $78 \%$ ) and Europe (7/9 nations, $78 \%)$ relative to those from Americas/Caribbean (8/12 nations, $67 \%$ ) and Asia/Oceania (9/16 nations, 56\%). The performance for India, the host of the 2010 Commonwealth Games, was also found to be negatively correlated with distance travelled $(r=-0.40)$. Thus, in theory not having to travel abroad or outside its own time zone to compete could make a positive contribution to India's performance in 2010. Nations that did not exhibit an inverse relationship between travel and performance (i.e. where $r>0$ ) were found to be generally those with relatively modest success in the Commonwealth Games (e.g. Cayman Islands, Jersey, Norfolk Island and St. Vincent and The Grenadines)

\section{Discussion}

The first key finding from the research was that, with the exception of England, all previous host nations experienced a positive host effect in the Commonwealth Games. It is difficult to comment on the statistical significance of these findings because of the size of the data set involved. The analysis is limited to at most 15 editions (or observations) for a host nation. Also, nations inevitably compete away from home more often than they do at home. This in turn creates a disparity between the number of home and away observations for each nation in the sample. For example, Australia has only three observations for home performance but twelve observations for away performance. Despite the limitations of the data, in descriptive terms, there is evidence of nations generally performing better when they have hosted the Commonwealth Games.

If we regard average away performance as a measure of nation quality then there appears to be no systematic relationship between the relative quality of a host nation and the extent of the home advantage. For example, both Canada and New Zealand benefit more at home than Australia. Similarly, the home advantage experienced by Malaysia and Jamaica is greater than that of Wales, but lower than Canada, New Zealand and Australia. In other words, traditionally stronger nations in the Commonwealth Games do not necessarily benefit from greater home advantage.

As to why such home advantage may exist, there are generally three factors that are perceived to be at work: the influence of the home crowd, home athletes' familiarity with local conditions, and the effects of travel. ${ }^{8,12-20}$ The last of these factors is particularly pertinent in the context of the Commonwealth Games where international travel is involved that can sometimes span several time zones. The research has shown that, as a general rule of thumb, a nation's performance in the Commonwealth Games progressively deteriorates the further its athletes travel away from their own time zone. A possible explanation for this finding is 'jet lag'. Previous research ${ }^{18}$ indicates that the severity of jet lag and subsequent recovery is a function of the number of time zones crossed. From a policy standpoint, the findings from the research should enable non-host nations to set pragmatic aspirations for success in the Commonwealth Games, allowing for any 'performance loss' associated with travel to the host location, particularly when the event is held in a different time zone.

Yet another candidate for home advantage in the Commonwealth Games is strategic in nature. This relates to the level of influence that a host nation can exert over the portfolio of sports, and the number of events contested within those sports, at its home edition. At present, the Commonwealth Games programme consists of a minimum of 10 sports, all which are mandatory. Article 21 of the Commonwealth Games Federation Constitution (http://thecgf.com/ about/constitution.pdf) states that a candidate city has the option to select up to seven further disciplines from a predetermined list of sports. Thus, host nations may opt to put forward sports and events that provide them with the best opportunity to win medals. Concurrently, organising committees may consciously minimise or omit disciplines in which competitor nations have a proven track record of success. This presents an area for future research to investigate how well host nations perform in optional sports rather than those that are mandatory.

Much of the media coverage surrounding the 2010 Commonwealth Games in Delhi has focussed on the city's preparation for, and capability of, staging the event. This issue has been further flagged following the recent abandonment of the fifth One Day International cricket match between India and Sri Lanka in Delhi due to an unfit pitch. Regardless of how well Delhi is progressing towards ensuring the successful delivery of the Commonwealth Games, on the field it is reasonable to expect an elevated level of performance from Indian athletes given the evidence presented in this paper.

\section{REFERENCES}

1. Balmer NJ, Nevill AM, Williams AM. Home advantage in the Winter Olympics (1908-1998). J Sports Sci 2001;19:129-139.

2. Balmer NJ, Nevill AM, Williams AM. Modelling home advantage in the Summer Olympic Games. J Sports Sci 2003;2:469-478.

3. Balmer NJ, Nevill AM, Lane AM. Do judges enhance home advantage in European championship boxing? J Sports Sci 2005;23:409-416.

4. Bray SR, Carron AV. The home advantage in alpine skiing. Australian Journal of Science and Medicine in Sport 1993;25:76-81.

5. Koning $\mathrm{RH}$. Home advantage in speed skating: evidence from individual data. J Sports Sci 2005;23:417-427.

6. McAndrew F. The home advantage in individual sports. Journal of Sports Psychology 1993;133:401-403.

7. Nevill AM, Balmer NJ, Winter EM. Why Great Britain's success in Beijing could have been anticipated and why it should continue beyond $2012 . \mathrm{Br}$ J Sports Med 2009;43: 1108-1110.

8. Nevill AM, Holder RL. Home ground advantage in sport: An overview of studies on the advantage of playing at home. Sports Med 1999;28:221 236.

9. UK Sport. Home advantage: The performance benefits of hosting major sporting events. UK Sport London; 2009.

10. De Bosscher V, De Knop P, Van Bottenburg M, Shibli S. A conceptual framework for analysing sport policy factors leading to international sporting Success. European Sport Management Quarterly 2006;6:185-215.

11. De Bosscher V, Bingham J, Shibli S, Van Bottenburg M, De Knop P. The Global Sporting Arms Race: An international comparative study on sports policy factors leading to international sporting success. Meyer \& Meyer Sport (UK) Ltd. Oxford; 2008.

12. Agnew JC, Carron AV. Crowd effects and the home advantage. International Journal of Sport Behavior 1994;25:53-62.

13. Carron A, Loughhead T, Bray S. The home advantage in sport competitions: Courneya and Carron's (1992) Conceptual Framework a decade later. J Sports Sci 2005;23:395-407.

14. Courneya KS, Carron AV. Effects of travel length of home stand/road trip on the home advantage. Journal of Sport and Exercise Psychology 1991;13:42-49.

15. du Preez M, Lambert MI. Travel fatigue and home ground advantage in South African Super 12 rugby teams. South African Journal of Sports Medicine 2007;19:20-22.

16. Jehue, R, Street, D, Huizenga R. Effect of time zone and game time changes on team performance: National Football League. Medicine \& Science in Sports \& Exercise 1993;25:127-131.

17. Nevill AM, Balmer NJ, Williams AM. The influence of crowd noise and experience upon refereeing decisions in Football. Psychology of Sport and Exercise 2002;3:261-272.

18. Pace A, Carron AV. Travel and the home advantage. Canadian Journal of Sports Sciences 1992;17:60-64.

19. Reilly T, Waterhouse J, Edwards B. Jet lag and air travel: Implications for performance. Clin Sports Med 2005;24:367-380.

20. Waterhouse J, Reilly T, Edwards B. The stress of travel. J Sports Sci 2004;22:946-966. 